Review

\title{
Microscale Strategies for Generating Cell-Encapsulating Hydrogels
}

\author{
Šeila Selimović $^{1,2}$, Jonghyun Oh ${ }^{1,2}$, Hojae Bae ${ }^{3}$, Mehmet Dokmeci ${ }^{1,2}$ and \\ Ali Khademhosseini ${ }^{1,2,4, *}$
}

1 Center for Biomedical Engineering, Department of Medicine, Brigham and Women's Hospital, Harvard Medical School, Cambridge, MA 02139, USA;

E-Mails: sselimovic@rics.bwh.harvard.edu (Š.S.); jonghyuno@gmail.com (J.O.); dokmeci1@gmail.com (M.D.)

2 Harvard-MIT Division of Health Sciences and Technology, Massachusetts Institute of Technology, Cambridge, MA 02139, USA

3 Department of Maxillofacial Biomedical Engineering and Institute of Oral Biology, School of Dentistry, Kyung Hee University, Seoul 130-701, Korea; E-Mail: hjbae@khu.ac.kr

4 Wyss Institute for Biologically Inspired Engineering, Harvard University, Boston, MA 02115, USA

* Author to whom correspondence should be addressed; E-Mail: alik@rics.bwh.harvard.edu; Tel.: +1-617-768-8395; Fax: +1-617-768-8202.

Received: 4 May 2012; in revised form: 28 July 2012 / Accepted: 2 August 2012 / Published: 5 September 2012

\begin{abstract}
Hydrogels in which cells are encapsulated are of great potential interest for tissue engineering applications. These gels provide a structure inside which cells can spread and proliferate. Such structures benefit from controlled microarchitectures that can affect the behavior of the enclosed cells. Microfabrication-based techniques are emerging as powerful approaches to generate such cell-encapsulating hydrogel structures. In this paper we introduce common hydrogels and their crosslinking methods and review the latest microscale approaches for generation of cell containing gel particles. We specifically focus on microfluidics-based methods and on techniques such as micromolding and electrospinning.
\end{abstract}

Keywords: hydrogel; lab-on-a-chip; micromolding; microfluidics; cell encapsulation 


\section{Introduction}

The field of tissue engineering aims to generate tissues in the laboratory for culture, drug screening, and ultimately for organ transplantation purposes [1-4]. To achieve this, cells are conventionally grown in mono-cultures or co-cultures, and seeded on or encapsulated inside biocompatible polymeric constructs [5-7]. These constructs are cultured in Petri dishes, stirred vessels or microfluidic devices. Inside these bioreactors, the polymer is degraded by the cells over time and replaced with the extracellular matrix (ECM), forming living tissue [8]. The polymer structure and other microenvironmental cues can affect the functional behavior of this in vitro tissue and should be chosen carefully.

Microscale technologies present an emerging set of techniques for manipulating biological materials in the context of tissue engineering. Major advantages of microscale systems include the need for only minute reagent and sample volumes, short experimentation times, (cost-)efficiency, and physical reduction of the experimental platform from the bench top scale to the micro- and milli-scale. The small experimental scale also allows for an independent control over several experimental parameters, e.g., number and density of cells or size and shape of the cell-laden polymer structure. This enables controlled handling of cells for encapsulation in natural or synthetic materials.

Microfabrication techniques have been employed in a variety of approaches to create three-dimensional (3D) cell-containing materials. This includes encapsulating cells in gel-based microdroplets $[9,10]$, forming cell-containing fibers and microtubes from gel precursor solutions, electro-spinning [11-13] and -spraying [14] polymers to generate gel droplets and fibers containing encapsulated cells, micromolding viscous cell suspensions into microscale particles [15-19], and printing biomaterials and cells on a substrate to generate tissue building blocks [20-24]. The resulting polymeric architectures are porous or permeable to small molecules, allowing nutrients and oxygen to reach the encapsulated cells and metabolic waste products to diffuse away from the cells.

In sum, the application of microscale strategies to generate cell-containing polymer structures offers a high level of control over the tissue building process. As such, it enables the development and study of replacement biological tissues. In this paper, we briefly introduce common hydrogels used in bioengineering and their prospective crosslinking methods. We then review recently developed microscale techniques and their limitations for generating cell-laden hydrogels. Finally, we discuss the applications of these microscale approaches in the context of tissue engineering and cell culture.

\section{Hydrogels for Cell Encapsulation}

One approach to tissue engineering involves encapsulating cells within size- and shape-controlled microscale gel structures. In addition to size and shape, the microgel allows researchers to control the cellular microenvironment. Advantageous properties of hydrogels for this purpose include their cytocompatibility, porosity and hydrophilicity. In this section, we will explain different strategies for crosslinking of hydrogels and their degradation behavior. 


\subsection{Hydrogel Crosslinking Strategies}

Hydrogels are three dimensional (3D) polymeric networks in which the hydrophilic polymer chains result in a swollen material upon exposure to water. Factors such as ionic concentration, $\mathrm{pH}$, or temperature may affect the amount of water taken up by hydrogels. Usually, in a swollen hydrogel the weight fraction of the polymer is small compared to that of water [25,26]. These properties allow for efficient transport of nutrients, growth factors and drugs to the encapsulated cells.

Hydrogels can be crosslinked by exposing the polymer precursors to chemical stimuli (e.g., enzymes and certain molecular functional groups) or by physical processes (e.g., ionic interactions, crystallite bonding and temperature changes).

Chemical crosslinking methods commonly generate covalent bonds between polymer chains to form hydrogels. In one approach, irradiation with ultra violet (UV) light, which generates radicals for the polymerization of acrylate groups, can be used to synthesize various gels [27-30]. In this process, acrylated macromers can be synthesized from various natural or synthetic polymers. For example, gelatin methacrylate (GelMA) can be synthesized by incorporating methacrylate groups into the gelatin molecules [18,28,31]. Also poly(ethylene glycol) (PEG) can be chemically modified to generate the UV-sensitive PEG-diacrylate (PEG-DA) [32-35]. These polymers can then be used to generate hydrogels by exposing the polymer to UV light in the presence of a photoinitiator. Radical-based cross-linking methods that utilize other wavelengths have also been developed, as e.g., visible wavelengths are less damaging to cells than UV-light [36,37]. For example, PEG-based hydrogels could be crosslinked under visible light with the addition of eosin $\mathrm{Y}$ as photosensitizer and triethanolamine as photoinitiator [36]. The resulting viability of encapsulated human mesenchymal stem cells was $10 \%$ higher compared to the UV-crosslinked case. In either case, the degree of crosslinking controls hydrogel swelling and mechanical properties [28,38,39]. Chemical reactions involving functional groups such as $\mathrm{OH}, \mathrm{COOH}$, and $\mathrm{NH}_{2}$ can also be employed for crosslinking. In crosslinking gels, aldehyde based reactions are common, with polyaldehyde groups linking polymer chains with hydroxyl and amine groups. For example, collagen can be crosslinked by polyaldehyde, obtained by dextran oxidation, which is suitable for cell encapsulation [40]. Another type of crosslinking agent involves enzymes. In the case of proteins such as lysozyme and casein, the enzyme tyrosinase acts as a crosslinker [40]. Furthermore, the enzyme Fibrin Stabilizing Factor, also known as Factor XIII, has been used to crosslink hydrogel precursors consisting of peptide-conjugated PEG [41], in the presence of calcium and thrombin. Although heat was needed for the crosslinking process, it was used to activate the enzyme rather than induce gelation of the precursor solution. Similarly, transglutaminase was applied as a crosslinking agent of protein polymers, as described by Davis et al. [42]. Crosslinking of hydrogels using enzyme is considered a cell-friendly method, as the gelation can occur at physiological temperature, $\mathrm{pH}$ and without the introduction of free radicals or UV light.

A common example of physical crosslinking is alginate, which can be crosslinked by the addition of divalent cations such as $\mathrm{Ca}^{2+}$ [43]. Another physical crosslinking method that can be applied to crosslink gels involves the formation of crystallites. For example, the crosslinking of PVA (poly(vinyl alcohol)) through maleic acid generates crystallites, which then gradually form a gel at room temperature $[44,45]$. Furthermore, changes in temperature can also be used to induce hydrogel 
formation. For instance, PNIPAAm (poly( $N$-isopropylacrylamide)) experiences a phase transition from aqueous liquid to gel at $34.3{ }^{\circ} \mathrm{C}$ [46]. The crosslinking processes listed here are compatible with microscale techniques for generating hydrogel particles. Additionally, they are potentially better suited to micro- than macroscale techniques. For example, diffusion-driven crosslinking processes are completed in a shorter time inside microstructures, and UV light is absorbed less by small and thin hydrogel layers than by thick ones, enabling a more uniform cross-linking of thin or small particles.

\subsection{Hydrogel Degradation}

Degradability is an important characteristic of cell containing materials in tissue engineering applications, although nondegradable hydrogels, such as PEG, can also be used in certain cases. In an ideal situation, as the hydrogels degrade, cells replace the existing structure with their own ECM. This is particularly important in the development of implantable tissue constructs for medical and therapeutic purposes. To degrade hydrogels, the hydrophilic backbone of the polymer chains can be broken down as a result of hydrolysis or enzyme activity [47,48]. Alternatively, gel degradation can be induced by digesting the crosslinker portion of the gel $[49,50]$. The rate of degradation can be accelerated by reducing crystallinity, raising the number of reactive hydrolytic group, and increasing porosity [51]. As a result of degradation, the hydrogel mass decreases and its mechanical stability is reduced. These properties could be advantageous for cell carrier applications [5,52], controlled release of drugs and growth factors [53,54], or tissue regeneration studies [55,56].

Hydrogels based on natural substrates such as collagen, chitosan, gelatin, fibrin, and hyaluronan are shown to be biodegradable $[57,58]$. Certain originally nondegradable synthetic hydrogels including PVA (poly(vinyl alcohol)) and PEG (poly(ethylene glycol)) can also be rendered degradable. This can be accomplished by the addition of ester or peptide functionalities in the crosslinking agents. For example, PVA can be modified with ester linkages [59] and PEG-based hydrogels can utilize crosslinkers based on cell-degradable peptides [41,60]. Thus, these hydrogels can be modified to become sensitive to and degradable by matrix metalloproteinases (MMP), which are expressed by cells to process the ECM and other bioactive molecules. All aforementioned hydrogels, including PVA and PEG-based hydrogels [52,61] are cytocompatible and can be used to encapsulate cells. Furthermore, these hydrogels can be shaped into microscale particles or fibers by various approaches including microfluidics, electrospinning, or micromolding.

\section{Microscale Technologies}

In the following sections we introduce different microscale methods for generating microgel structures. These include soft lithography, photolithography, bioprinting as well as various microfluidic methods, electro-spraying and -spinning. All techniques described here allow for the generation of microstructures containing only gels, as well as microstructures containing gels and cells. Hence, in each section we first discuss the general hydrogel structure generation method, and then present it in the context of cell-containing hydrogels. 


\subsection{Soft Lithography}

The term "soft lithography" describes a set of methods for using elastomeric, rubber and polymer structures based on replica molding and self-assembly, and it includes techniques such as micromolding and capillary molding [16,17,62]. Cast and replica molding [63,64] methods commonly utilize chemically crosslinked materials, such as the ubiquitously used poly(dimethylsiloxane) (PDMS). PDMS is a visually transparent two-part elastomer, consisting of a liquid base similar to silicone oil and a hardening agent [65]. Upon mixing, the two components begin to form chemical links at junctions of interacting polymer strands; this curing process proceeds at room temperature but can be thermally accelerated. When poured or spin-coated on a solid master, the liquid mixture conforms to all features and hardens within one to a few hours. Naturally hydrophobic, PDMS can be made less toxic for certain cell culture applications by removing uncrosslinked PDMS molecules [66]. It can also be further functionalized to allow for cellular attachment, e.g., by surface patterning with proteins such as fibronectin. Nonetheless, PDMS is preferentially used as a master for micromolding of hydrogel particles, such as PEG or GelMA [67], rather than for direct cell encapsulation.

In microtransfer molding [68] a liquid prepolymer is applied to a crosslinked PDMS master such that the liquid fills out all crevices in the master. The excess liquid is then squeezed out with a glass slide. The prepolymer is allowed to solidify and remains adherent to the glass slide when the master mold is removed. This method usually yields structures that are a few $\mu \mathrm{m}$ to $\sim 150 \mu \mathrm{m}$ thick, although thicker shapes can also be formed. Alternatively, a PDMS master can be pressed onto a liquid prepolymer, forcing the liquid to fill the empty spaces prior to crosslinking [27]. Cells can be encapsulated in the resulting gel structures simply by suspending them in the gel prepolymer solution. For example, using this method NIH-3T3 fibroblasts were encapsulated in a hydrogel based on methacrylated hyaluronic acid [27]. In addition, Tekin et al. [69,70] showed that thermoresponsive micromolded hydrogels could be used when dynamic microparticles and -molds were required. The swelling and shrinking properties of hydrogels can be exploited in dynamic applications, such as when a change in pore size of the hydrogel is desired. This effect can be used to control the permeation of biomolecules through the particle [71]. Additionally, any cells and cell aggregates in contact with a dynamic hydrogel experience the changes in scaffold size as a shift in the scaffold topography and respond to it. To achieve this effect, Tekin used PNIPAAm in conjunction with agarose, another thermoresponsive material, and encapsulated human umbilical vein endothelial cells (HUVEC), NIH-3T3 fibroblasts and HepG2 cells in the hydrogels. Individual PNIPAAm master structures were fabricated on a flat substrate. By controlling the surrounding temperature, the structures could be induced to shrink or expand. Then, a second hydrogel prepolymer, agarose, was deposited in the spaces between the PNIPAAm master structures and crosslinked to form microparticles. Upon changing the ambient temperature, the PNIPAAm particles swelled, thereby pushing on the agarose microparticles until they detached from the substrate. Thus, this method utilized dynamic microstructures to generate a secondary set of agarose microparticles.

Similar to microtransfer molding, micromolding in capillaries [72,73] requires that the liquid prepolymer fills narrow capillary channels formed by a PDMS master and a glass slide, where it solidifies. The prepolymer is drawn into these microscale channels by capillary force. This has been observed in microcapillary channels with both open and closed ends. Inside closed channels the 
trapped air diffuses into PDMS, allowing the advancing prepolymer solution to completely fill the capillary. Micromolding in capillaries has been used to pattern UV-sensitive polymers such as polyacrylates [74] as well as macromolecules such as immunoglobulins [75].

A typical example of micromolding using a solid 3D pattern is shown in Figure 1a, where a liquid low-temperature gelling agarose solution was heated to $70{ }^{\circ} \mathrm{C}$, applied to a patterned silicon substrate and allowed to solidify. Upon gelation at room temperature, the $1 \mathrm{~cm}$ thick agarose layer containing the pattern imprint was peeled off and sealed with a separately prepared flat agarose slab to generate a hydrogel microchannel. Cells were encapsulated in the gel using the same process, resulting in a high initial viability, indicating that the brief variation in temperature did not have a strong cytotoxic effect. This channel was utilized for perfusion of encapsulated cells with culture medium to mimic blood vessel-like structures. It was shown that cells residing closest to the fluidic channel had the highest viability, due to the diffusion of media into the porous gel.

One drawback of soft lithographic techniques is a reduction in feature quality at high height to width ratios. Namely, during removal of the master, hydrogel structures with high aspect ratios tend to stick to the master material and either break or are distorted. This limitation is lifted in master-less methods such as photolithography.

Figure 1. (a) Micromolding of agarose hydrogel from a silicon master; (b) Photocrosslinked gelatin methacrylate (GelMA) hydrogels containing human umbilical vein endothelial cells (HUVEC), in phase contrast and fluorescence; (c) (i) Photolithography for microgel fabrication and surface-directed assembly of the microparticles; (ii) Assembly of secondary gel structures without a second crosslinking step; and (iii) with $8 \%$ and (iv) $12 \%$ of the prepolymer solution as binding agent in the second crosslinking step. Figures adapted and reprinted with permission from [76] (a), [18] (b), and [77] (c).

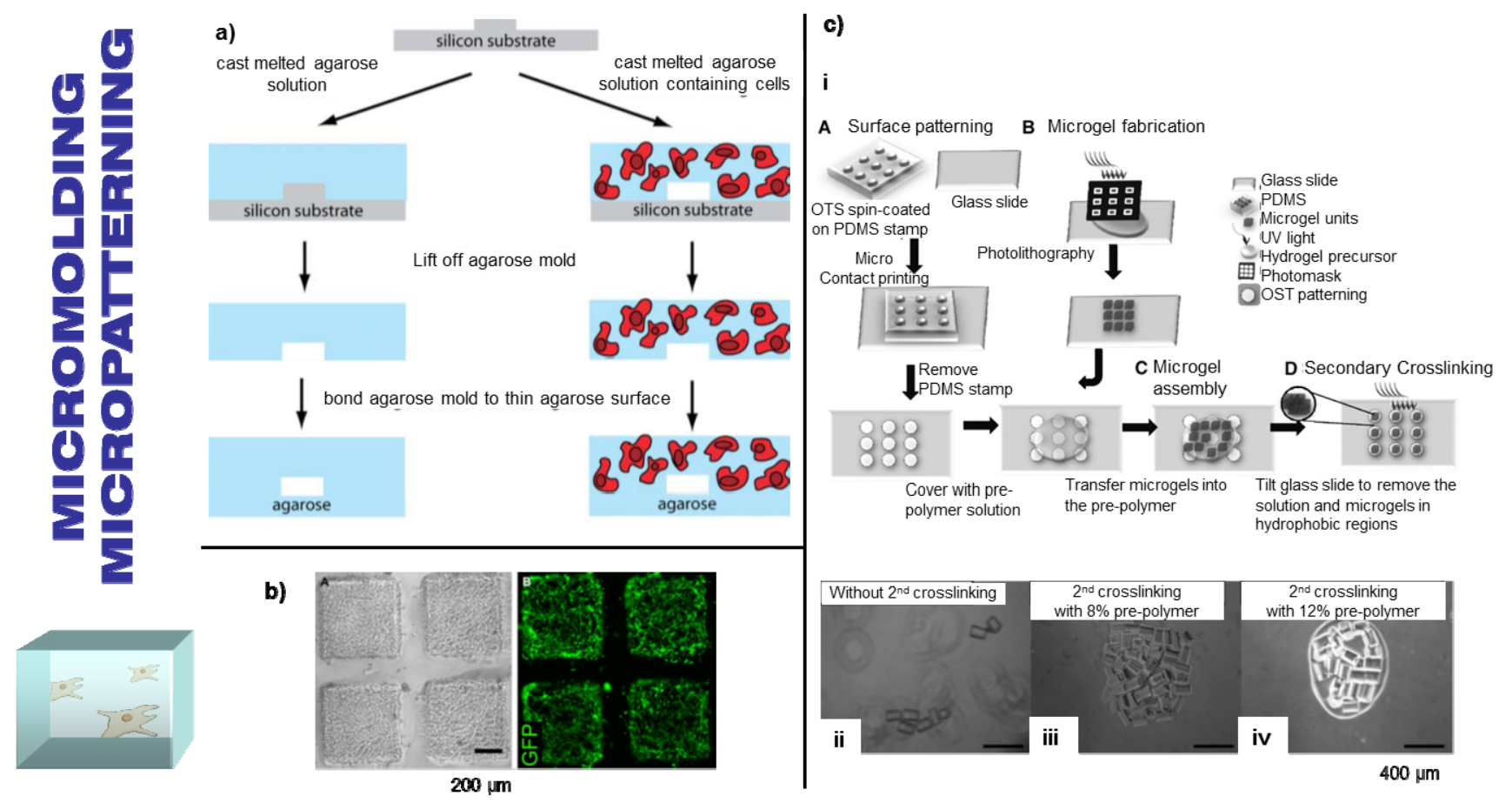




\subsection{Photolithography}

Hydrogel precursors can be engineered to crosslink using light [30,78,79]. In these photocrosslinking applications, liquid materials (i.e., photoresists, gel precursors) are shaped into hard structures by inducing radical-based photosensitive reactions. The energy necessary to initiate the photosensitive chemical reaction is usually delivered by light in the UV range, although other wavelengths can also be used [36,37]. More specifically, in photolithography the photoresponsive material can be deposited onto a substrate and exposed to light through a photomask, which can be printed on a transparency or chrome substrate. The areas of the photosensitive material accessible to light are crosslinked based on the pattern of the mask. The covered areas remain liquid and can be removed by washing with a developing agent. The generated polymer patterns have the same height and can be considered planar. To form more complex 3D features, several repetitions of the process are necessary. In each step, a new layer of the prepolymer is introduced and exposed to light under a different mask [15].

In certain photosensitive materials, such as photoresists, UV light is absorbed by molecules that generate a photoacid. In doing so, they release protons. The formed photoacids activate the ring-shaped epoxy groups and function as photoinitiators (initiators of the polymerization process). Hereby new protons are released and can facilitate another polymerization reaction [80]. Similar free radical polymerization reactions take place in a range of polymers and biomaterials [78], such as PEG-DA (PEG-diacrylate) [81,82], poly(oligo (ethylene oxide) monomethyl ether methacrylate) [83], MeHA (methacrylated hyaluronic acid) [27,84] and GelMA [18,31]. Although free radicals can be damaging to cells, this radical-based photolithography process can be made cell-compatible by carefully choosing the photoinitiator and the energy of UV delivered to the encapsulated cells.

Encapsulation of cells inside photolithographically fabricated gel structures requires suspending the cells in the prepolymer prior to UV-exposure. Figure 1b shows photo-crosslinked GelMA particles on a PEG-coated surface with HUVEC adhering preferentially to gelatin [18]. Similarly, NIH-3T3 fibroblasts that were encapsulated in the GelMA particles remained viable and confined to these particles, rather than migrating onto the PEG-substrate, which lacked appropriate adhesion sites. Another example of photolithography is shown in Figure 1c (i). This figure details the method of PEG-DA microgel fabrication via UV-exposure [77] and subsequent microgel assembly on a hydrophilic patterned surface. The generated microparticles were 50 and $150 \mu \mathrm{m}$ tall with lateral dimensions of 50 to $400 \mu \mathrm{m}$. To create larger structures, the particles were allowed to self-assemble in a drop of PEG-DA precursor solution (Figure 1c, ii). They were then exposed to UV light a second time, with the PEG-DA prepolymer as the bonding agent. The addition of this bonding agent helped increase the physical stability of the assembled particles (Figure 1c, iii-iv). Although UV light can be damaging to cells, it was shown that encapsulated NIH-3T3 cells remained viable even after the second crosslinking step.

Other photolithographic polymerization reactions have been developed, which rely on donor/acceptor pairs instead of photoinitiators, but are not suitable for cell-encapsulation applications [85]. In all photolithography applications, however, the patterning process is sensitive to the exposure time, since the crosslinking reactions continue beyond the UV-exposure. For example, a long exposure time can lead to diffusion of the propagating species (i.e., free radicals) into unexposed 
regions of the prepolymer. This can result in features with trapezoidal rather than rectangular cross-sections. A different kind of irregularity is introduced into particles when they are UV-crosslinked while flowing inside a capillary or microfluidic channel. Depending on the applied flow rate and the exposure time, the particles can appear smeared. A solution is offered by stop-flow lithography, where the flow is suspended for the duration of exposure and then quickly reinstated [86].

The presented photolithographic approaches for generation of microgel particles are compatible with cells and offer planar geometries. However, a true 3D structure can be introduced via two-photon lithography [87-89]. In this method, a material simultaneously absorbs two photons of equal or different wavelengths to reach a transitional energetic state, which is otherwise inaccessible. While single photon absorption is characterized by a linear relationship between absorption rate and light intensity, in two-photon lithography the absorption rate increases with the square of the light intensity. Thus, the material polymerizes much faster in the vicinity of the photon's focal region than a short distance away. By moving the sample relative to the laser beam, only the material in focus is being polymerized. Hence, two-photon lithography allows for selective 3D crosslinking of a gel precursor solution.

\subsection{Microfluidics}

\subsubsection{Hydrodynamic Focusing}

Recently, microfluidic approaches have been utilized for fabricating well-controlled spherical or rounded gel microparticles, as well as cylindrical and hollow gel fibers. These are shapes that cannot be easily formed using soft or photolithography techniques. Furthermore, microfluidics offers the ability to continuously alter the particle shape and size, simply by changing the flow rate of the prepolymer solution. It does so without the need for masks and masters and is compatible with cells.

Cells and particles can be manipulated with excellent fidelity inside micrometer-sized channels or chambers [90,91], enabling experiments that require tightly controlled cellular microenvironments [3,92-97]. This and other biomedical engineering applications of microfluidics have been discussed in the context of drug discovery [98-100], stem cell biology [101,102], oncology [103], controlling cellular behavior (i.e., angiogenesis, migration, cellular interactions) [104-106], and tissue culture [98,100,107-110]. Specifically, issues concerning 3D cell-tissue complexes have been addressed, including adequate perfusion of tissues with nutrients and gases [111] as well as their stimulation with chemical, mechanical and electrical signals [112].

One of the most popular applications of microfluidics for generation of cell-containing materials relies on hydrodynamic (flow) focusing in glass capillaries and nozzles to encapsulate cells inside droplets or jets of polymer solutions. These structures are based on the laminar flow of the sample framed by an immiscible phase. The sample either includes cells suspended in an uncrosslinked hydrogel or two separate streams of cell solution and a hydrogel. The inner or dispersed phase of the resulting flowing structures is usually an aqueous solution. The outer, continuous phase is commonly a non-toxic oil such as corn oil (water-in-oil emulsion) or a lower-viscosity aqueous solution (water-in-water emulsion). The flow rates of all streams are adjusted to enable shearing off of individual droplets of the inner phase, due to the shear stress caused by the continuous phase. This 
setup allows for the generation of droplets containing the hydrogel prepolymer, with or without cells, even in water-in-water emulsions. Such emulsions take advantage of the difference in viscosity of the two miscible phases, such that for a brief period the two phases can be considered immiscible. A successful water-in-water emulsion has been demonstrated by Capron et al., who emulsified an alginate hydrogel solution in sodium caseinate [113]. Similarly, microemulsions of dextran were generated in an aqueous PEG solution, by stirring [114] and by microfluidic flow focusing [115]. In the first case, methacrylated dextran (dexMA) was used, which allowed for photocrosslinking of the gel precursor. In addition to flow focusing, hydrogel droplets can be generated in T-junction microfluidic structures. In this case, the aqueous and lipid phases do not co-flow and aqueous droplets are periodically sheared off by the faster flowing oil stream. In both flow focusing and T-junction devices, the use of a lipid phase can act to decrease the cell viability. Even when non-toxic liquids like corn oil are applied to shear off hydrogel droplets, the encapsulated cells near the droplet and particle surface are in contact with the surfactant and the oil. Then, the amount of nutrients available inside the microparticles is often only sufficient for a short culture period, especially in densely packed particles. Hence, it is important that the crosslinked particles be washed soon after fabrication and moved to a reservoir containing cell medium. Further, the washing process should be gentle, avoiding solvents and high centrifugation rates.

Several studies highlight the encapsulation of cells in hydrogel droplets using microfluidics. For example, Shintaku et al. introduced independently an alginate solution and a solution containing $\mathrm{Ca}^{2+}$ ions into a microfluidic channel and established a brief co-flow of the two species. Droplets of the aqueous solutions were sheared off periodically due to the shear stress caused by the high flow rate of oil[116]. Individual alginate droplets were shown to gel by adding $\mathrm{Ca}^{2+}$ ions, which replace $\mathrm{Na}^{+}$ions as they diffuse through the droplets. Decreasing the crosslinker flow rate and increasing the flow rate of alginate resulted in a reduced droplet size. Furthermore, mechanical properties of the gel were affected by the degree of crosslinking, which depended on the crosslinking time and the crosslinker concentration. Similarly, single Na-alginate emulsions could be formed at the tip of a rotating micronozzle by gravity and cross-linked in $\mathrm{CaCl}_{2}$ solution [117]. The droplet size was controlled using the inner nozzle diameter and its speed of rotation.

The flow focusing setup used for simple hydrogel microdroplet generation also enables the formation of so-called Janus droplets (Figure 2a,b). These droplets contain two distinct halves, which are generated by two miscible, co-flowing sample solutions. Such heterogeneous structures are of interest in cell co-culture applications. The Janus particle generation technique is highlighted in Figure 2a. Here, suspensions of carbon black and titanium oxide particles in an acrylic monomer solution were co-flowed to produce Janus microspheres with white and black halves in an aqueous solution [118]. The gel was thermally crosslinked outside the fluidic module. Non-spherical Janus microparticles could also be generated, as shown by Prasad et al. [119], who produced dyed micro-dumbbells with distinct organic and inorganic polymer regions (Figure 2b). Finally, Seiffert et al. showed that even more complex particles could be generated, containing three distinct units [120,121]. In their experiment, the standard two miscible phases (labeled with fluorescent green and red dyes) were complemented by a third hydrogel precursor solution prior to UV-crosslinking.

Multiple emulsions can be generated by forming droplets inside other droplets. This method requires the use of two or more nozzles or capillaries for flow-focusing. The emulsification procedure 
is independent of the presence of cells or other particles inside the liquid streams, so we first consider examples containing only the gel precursor. We subsequently review recent works utilizing cell-containing, multiple emulsion gels. Standard double emulsification methods include the single-step and double-step double emulsion techniques. The first was used to generate cell-compatible PNIPAAm microparticles with a core and shell (Figure 2c,d) [122]. The latter technique (Figure 2d) was exemplified in the encapsulation of a hydrophobic magnetic monomer solution surrounded by an acrylamide shell in fluorocarbon oil [123]. Although this particular double-emulsion example is not cell-compatible, it depicts an emulsification method that is generally compatible with cells and hydrogels. Usually, double emulsion methods lead to water-oil-water emulsions. The exact order of the inner, middle, and outside phases can be reversed, as long as the contacting phases are immiscible. Recently, however, water-water-oil emulsions have also been demonstrated: Yasukawa and colleagues [115] created monodisperse droplets of dextran in aqueous PEG, surrounded by hexadecane. Higher level emulsions were successfully demonstrated by Weitz and coworkers [124]. Their capillary systems offer excellent control over the number of encased droplets in double-, tripleand higher emulsions. This was exemplified in the generation of a triple emulsions of the temperature sensitive PNIPAAm hydrogel [125]. Here, hydrogel shells encased up to ten aqueous droplets floating in oil. A rapid increase from room temperature to $50{ }^{\circ} \mathrm{C}$ led to shrinking of the hydrogel. As a consequence, the aqueous droplets were expelled from the microcapsules. This observation depicts such multiple emulsions as potentially suitable for cell encapsulation and controlled cell release.

Figure 2. (a) Single-emulsion flow-focusing setup for generation of acrylic Janus particles; (b) Polymeric, dumbbell-shaped Janus particles; (c) Single- (left) and double-emulsion (middle) flow-focusing configuration for formation of Poly( $N$-isopropylacrylamide) (PNIPAAm) particles (right); (d) Core-shell magnetic acrylamide microparticles with single and two cores. Figures adapted and reprinted with permission from [118] (a), [119] (b), [122] (c), and [123] (d).

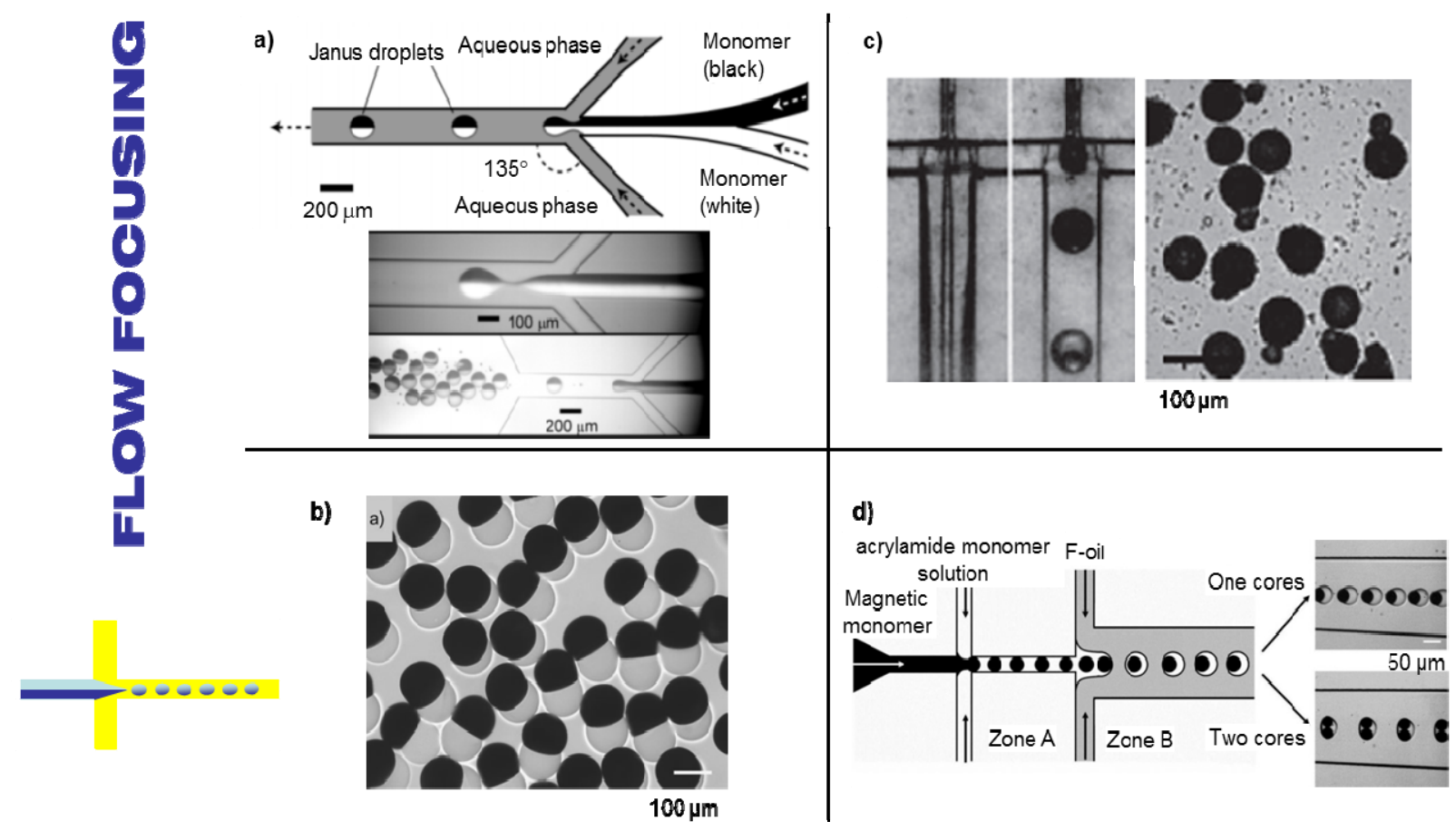


In all emulsions, the microdroplets are crosslinked into solid particles by chemical, thermal, or UV-initiated reactions. There are four main advantages in utilizing drop-generating microfluidic techniques: the high throughput capacity to generate millions of droplets per hour, uniform droplet sizes achieved by added surfactants, excellent regulation of droplet size and spacing via flow rate adjustments, and control over the average number of encapsulated cells. For example, a decrease in the flow rate of the dispersed phase relative to the continuous phase yields smaller droplets. Additionally, an increase in the continuous phase flow leads to a wider droplet spacing. Moreover, the mechanical properties of the resulting microgels can be adjusted by altering the rates of the hydrogel precursor and crosslinker flows.

The individual hydrogel droplets, spherical particles and fibers are sufficiently small to enable efficient permeation by gases, water and small molecules. The resulting high cell viability is a major advantage of using such gel structures for cell encapsulation. Thus, there are many examples of encapsulating cells inside hydrogel droplets. For example, a microfluidic T-junction was used to encapsulate $E$. coli in monodisperse droplets of PEG-DA (Figure 3a). The droplets were then photocrosslinked and the cells remained viable after overnight incubation [126]. Similarly, PEG-based microdroplets laden with NIH-3T3 fibroblasts were formed after stirring of the aqueous solution in mineral oil and photocrosslinking [127]. In another application, PEG-DA was mixed with a suspension of mammalian cells and patterned into cylindrical microstructures inside a microfluidic device [128]. The cell-laden structures were cultured for a week, and the cells retained high viability and enzyme activity throughout that period. Furthermore, an example of monodisperse alginate beads containing Jurkat cells is shown in Figure $3 b$ [129]. Here, the effect of $\mathrm{CaCO}_{3}$ crosslinker concentration on cell viability was studied. It was reported that lowering the crosslinker concentration led to improved cell viability. Franco et al. [127] later demonstrated successful encapsulation of neural stem cells in PEG-DA microspheres (Figure 3c). Additionally, the microfluidic flow focusing structure was employed to generate double-emulsions from two hydrogels and selectively trap cells in the inner or outer phase [130]. In this work, a highly viscous dextran suspension of Jurkat cells was co-flowed with a low-viscosity PEG solution. Due to the mismatch in viscosity, a dextran droplet was regularly enclosed inside a PEG droplet.

Chemically polymerizing hydrogels were also used for formation of spherical cell-laden microparticles. For example, Um and others (2008) first generated a hydrogel mixture of puramatrix and alginic acid [131]. A hydrogel precursor droplet containing HepG2 cells was then merged inside a microfluidic device with a drop of $\mathrm{CaCl}_{2}$ crosslinker. Mixing of the prepolymer solution and the crosslinker in this way led to controlled hardening of the droplet. This high-throughput particle generation technique is useful for a variety of cell-based assay applications, e.g., drug screening. Another example of cell-laden particles based on peptides is shown in Figure 3d [132]. A self-assembling peptide (SAP) hydrogel precursor was mixed with a suspension of endothelial cells. Hydrogel droplets in mineral oil were formed in a flow focusing setup. The ionic cross-linker was delivered to the droplets in the form of powdered salt inside the oil phase. The encapsulated cells were observed to migrate and proliferate within the particles after a 3-day culture. Thus, since SAP hydrogels can promote cell adhesion, spreading, and differentiation, this technique is suitable for tissue engineering applications. 
Figure 3. (a) E. coli encapsulated in poly(ethylene glycol)-diacrylate (PEG-DA) particles; (b) Alginate beads containing Jurkat cells; (c) Live (green) and dead (red) neural stem cells captured inside PEG-DA microspheres; (d) Endothelial cells inside self-assembled peptide microparticles. Figures adapted and reprinted with permission from [126] (a), [129] (b), (c) [127], and [132] (d).

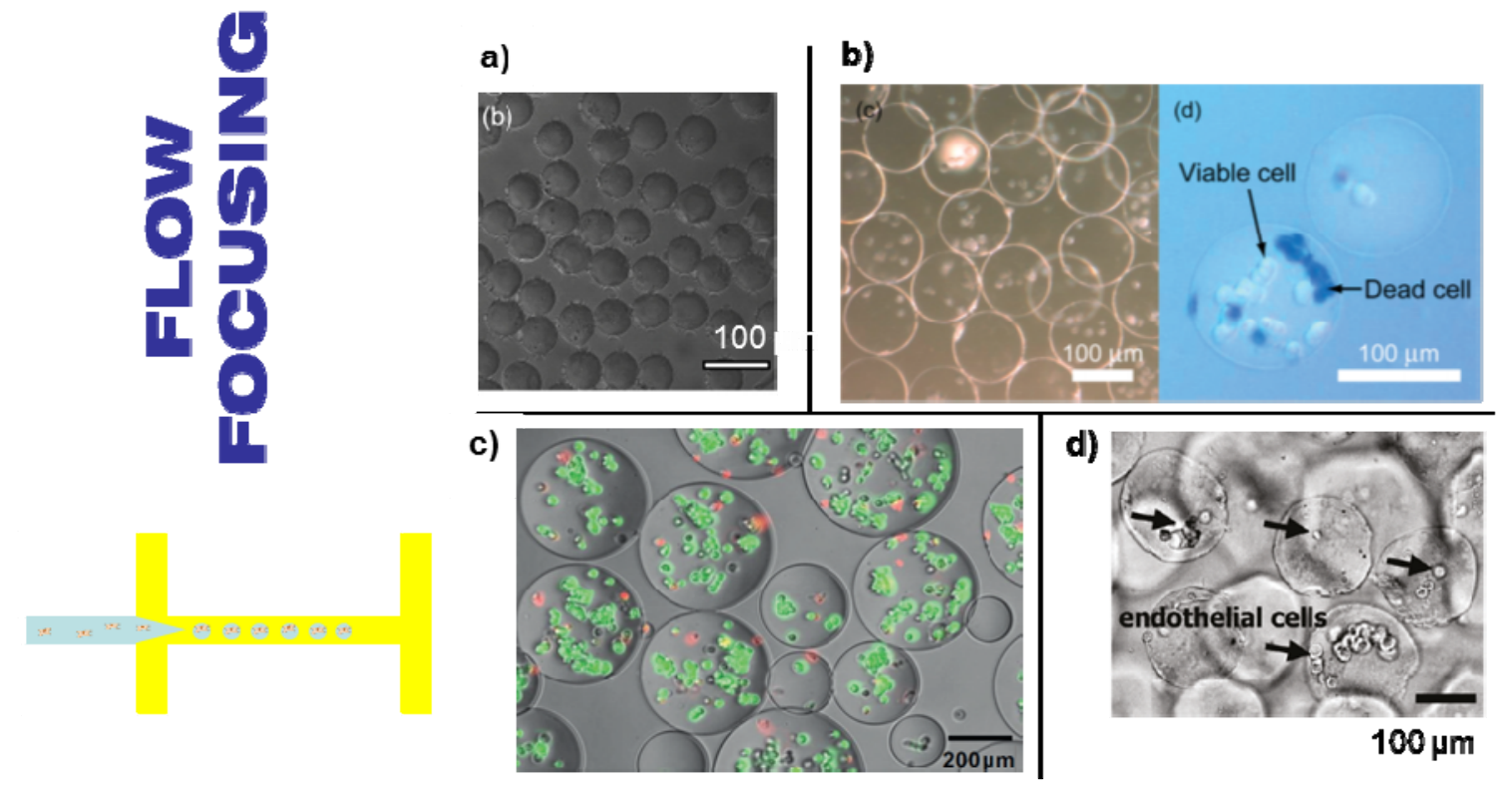

\subsubsection{Jetting in a Coaxial Configuration}

In a coaxial flow arrangement of glass capillaries or inside a microfluidic device, a jetting regime can often be observed in addition to the dripping or drop-making regime. In the jetting regime [124,133], the surface tension of the inner phase needs to be overcome by its Laplace pressure before the jet becomes unstable and droplets can be formed. The droplets are usually formed far from the nozzle or flow junction. Beyond the jetting regime, the cylinder of liquid simply flows along a channel or capillary without breaking up. It is in this region that polymer fibers and hollow cylinders can be formed [134,135]. For example, Kang et al. [136] used a flow-focusing setup to generate long gel microfibers with varying topography, e.g., by including air microbubbles or altering the flow rates. They could also alter the chemical structure of the fiber by alternating flows of different alginate mixtures. In this manner the hydrogel fibers could be spatially coded with either different hydrogels or different cell types. An example is shown in Figure 4. Here, the continuous flow of an alginate precursor solution was sequentially joined with a suspension of fibroblasts, followed by a suspension of primary rat hepatocytes and alternating with a merged flow of the two cell suspensions. The precursor solution gelled during the flow, such that a single long fiber with different cell-containing regions could be produced. Furthermore, Yeh et al. [137] utilize the jetting regime to generate solid microfibers from chitosan with tripolyphosphate as crosslinker. However, since these two materials individually have non-physiological $\mathrm{pH}$ values, cells could only be seeded onto the fiber surface after gel crosslinking and neutralization. Fibers were also generated in microfluidic devices from amino acid based polymers, namely $N$-carboxyanhydrides with triethylamine as crosslinker[138]. Finally, Hu et al. used PNIPAAm to form hollow fibers in co-axial microfluidic structures [135]. Because no oils are 
required in this technique, as opposed to the previously discussed droplet generation methods, jetting is considered to be more cell-friendly. However, the resulting microstructures are limited to fibers and hollow cylinders.

Figure 4. (a) Schematic and micrograph (inset) of an alginate microfiber, spatially coded to include either fibroblasts, rat hepatocytes, or a mixture of the two cell types. In the first case the cells were coded into the fiber serially; in the latter case the coding was parallel; (b) Higher magnification micrograph of a fiber section containing the cell co-culture. Figures adapted and reprinted with permission from [136].
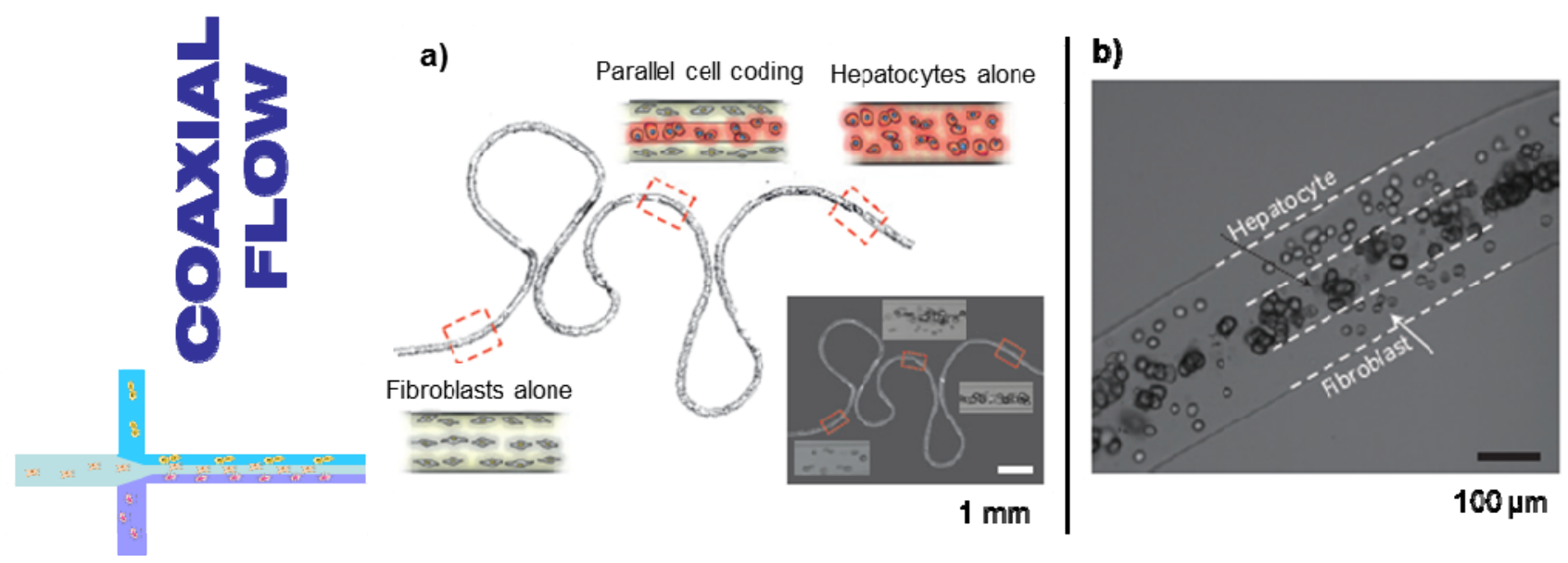

\subsection{Extrusion of Gels for Cell Encapsulation}

\subsubsection{Electrospraying and Spinning}

Aside from microfluidics, electrospraying and electrospinning are two methods that can also be used for generation of cell-containing gel particles and fibers. Nanoscale polymer fibers generated through electrospinning are commonly arranged in large porous network. Cells can attach to and proliferate within such a structure. However, in this section we focus on microscale fibers, which are sufficiently large for cell encapsulation.

The physics of electrospinning and -spraying in hydrogels can be summarized as follows: Applying a large electrical potential to a prepolymer solution dripping from a syringe needle leads to charging of the droplets. When surface tension is smaller than the resulting electrostatic repulsion, the droplet stretches until a stream of liquid is formed. At low surface tension droplets begin to form (electrospraying). In contrast, at a sufficiently high surface tension, the charged liquid stream remains stable (electrospinning) [139]. In the latter case the jet dries and charges concentrate on the jet surface. Electrostatic repulsion again drives the lengthening of the jet. The generated hydrogel stream is finally deposited onto a substrate, where it gels into fibers. The final shape of the electrospun fiber is controlled by several parameters: the inner diameter of the needle; applied electrical potential and flow rate; the molecular weight, viscosity and concentration of the material; and the distance between the needle and the collection substrate. Commonly, both electrospinning and -spraying setups rely on a single syringe pump to drive the flow. However, a droplet microfluidic setup can be used as an alternative. Hong et al. demonstrated that a flow-focusing setup could be applied to generate droplets 
prior to their exposure to an electric field [140]. By adjusting the droplet size and spacing they were able to control the number of encapsulated particles in each droplet.

The electrical potentials applied in these techniques are usually on the order of 0.1 to a few $\mathrm{kV}$. The applied currents are in the $\mathrm{mA}$ range. These electrospinning and -spraying conditions have been reported as cell-compatible. For example, it was shown that by co-flowing a biosuspension with a polymer solution through two nested energized needles, it was possible to electrospin fibers of medical-grade PDMS containing pockets of cells and media (Figure 5a), without deleterious effects of the electrical potential on the cell viability [12].

Furthermore, Jayasinghe and colleagues successfully encapsulated living immortalized human embryonic kidney cells inside PEO- and PVA-based electrospun fibers, and inside electrosprayed spherical alginate beads [141]. An investigation of annexin expression in these cells over 5 days showed that the cell activity was comparable to a control population. It was concluded from these results that the applied electrical potential did not strongly affect the cell viability. Embryonic stem cells have also been encapsulated in electrosprayed bio-polymer particles, and retained high viability and pluripotency [14]. Finally, the inner structure of the electrospun fibers was shown to be controllable.

Figure 5. (a) Electrospun poly(dimethylsiloxane) (PDMS) fibers containing pockets filled with media and cells; (b) Smooth fibers consisting of a bacteria-laden polyethylene oxide (PEO)-core and a polycaprolactone (PCL)-PEG shell; (c) Sketch of a bioprinting setup for formation of alginate gel structures (top), a branched alginate structure (middle) and a micrograph of the structure material at 40x magnification (bottom). Figures adapted and reprinted with permission from [12] (a), [142] (b), and [143] (c).
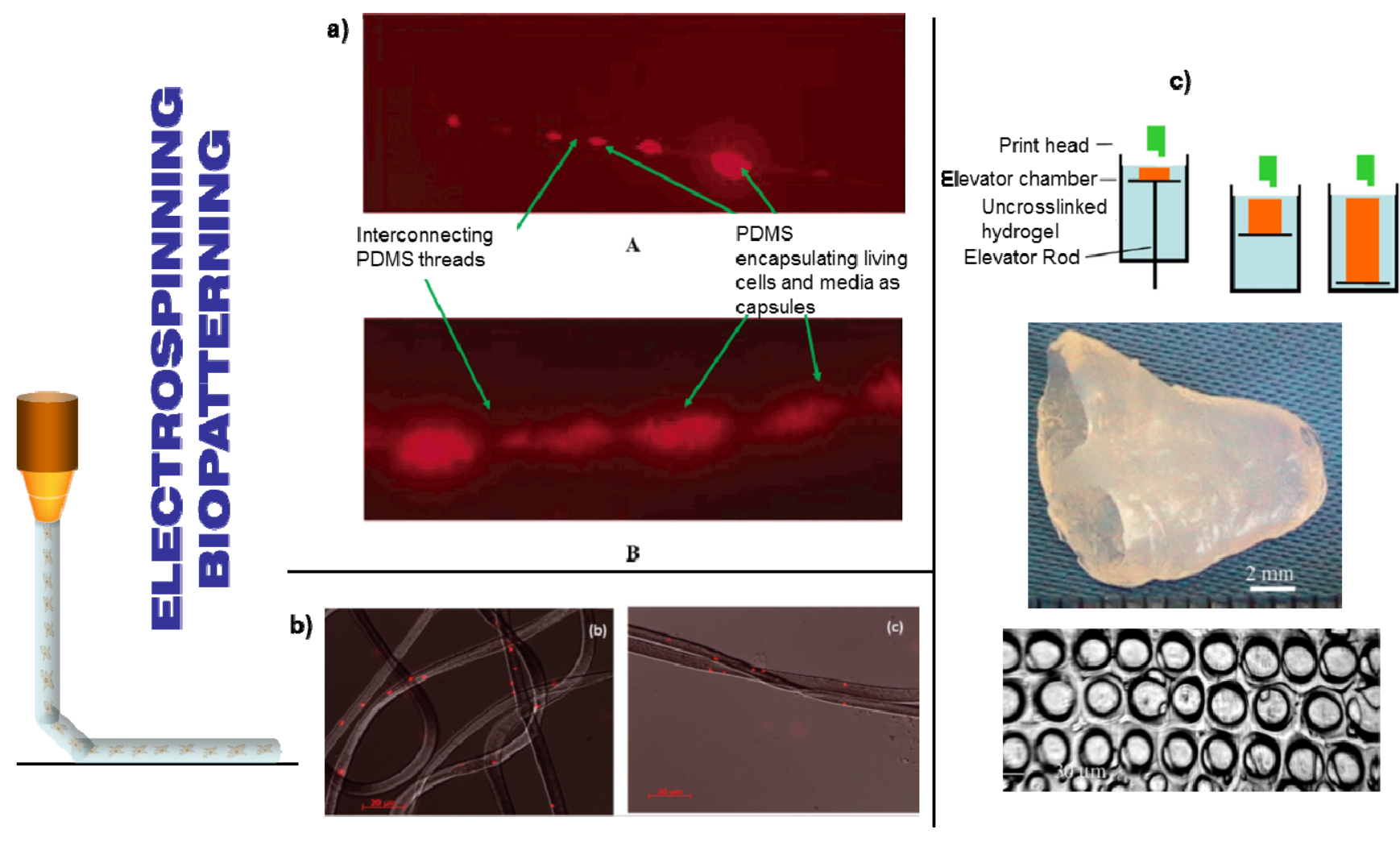
As an example, Klein et al. [142] suspended Pseudomonas putida bacteria in electrospun microtubes with porous walls (Figure 5b). The polyethylene oxide (PEO) based polymer solution and the bacterial suspension were flowed together through the inner of two coaxial needles. A polycaprolactone (PCL)-PEG-based shell polymer solution flowed through the outer needle. Evaporation of the solvent rendered the generated fibers porous. This strategy could potentially be exploited to form porous cell-containing materials with improved oxygen and nutrient transport. It should be noted that the electrospun fibers are deposited on a substrate along not predictable paths, making the controlled spatial placement of such fibers difficult. This is beneficial for generating larger hydrogel units containing cells, e.g., sheets with dimensions on the order of $\mathrm{mm}$ and even $\mathrm{cm}$. However, if spatial organization of the generated fibers is important, then bioprinting is a more appropriate approach.

\subsubsection{Bioprinting}

A major goal of tissue engineering is to develop viable 3D models of tissues and even organs. These models would then be used to study the effects of drugs and diseases inside the body [144,145]. Generating full organs in a laboratory is extremely complex. Therefore, usually only parts of individual tissues are grown [146,147]. However, there are ways to pattern these tissues in ways that represent their natural counterparts. Bioprinting is one such recent approach to creating 3D tissues in vitro, via cell-laden microgels. The bioprinting technique utilizes computer-controlled deposition of cells and structural materials such as hydrogels [21]. By imposing cell patterns using a robotic printing head, the cells naturally migrate and proliferate in the prescribed patterns [148]. The printed matter is then polymerized and transferred into an incubating chamber for culture. The incubating chamber can be fashioned out of a simple Petri dish, or a complex microfluidic device outfitted with perfusion channels, stimulation electrodes, and pulsatile flow controls [149]. In some cases, a large cell-encasing polymer structure can be replaced with small hydrogel units. This was demonstrated by Norotte et al., who showed that mm-sized agarose rods could be deposited on a substrate in a preprogrammed pattern [150]. These rods were used to direct the placement of the printed cell aggregates. The combined hydrogel and cell patterns then generated cylindrical, functionally homogeneous and also heterogeneous structures. The bioink containing the cell suspension and the biodegradable hydrogel are printed layer by layer. As a result, complex, preprogrammed 3D cell patterns inside the resulting structures can be generated, a feature that is challenging to achieve using jetting or electrospinning. A schematic of the bioprinting process and a printed branched alginate structure are shown in Figure 5c (top and middle). A light micrograph of the structure can be seen in Figure 5c, bottom [143].

Two types of bioprinters are commonly used: retro-fitted inkjet printers and extruders. Inkjet printers are affordable and simple to adapt to printing biological matter, but are often clogged with large cell aggregates [151,152]. Conversely, pressure-driven extrusion devices tend to be costly, but are better suited to applications utilizing high cell concentrations [153]. Commercial bioprinters include high precision pressure and temperature controllers to keep cells viable and maintain a low-viscosity polymer solution. These bioprinters also utilize several printing heads for simultaneous printing of several structures. Alternatively, multiple printing heads can be used for printing different cell types and biomaterials. 
Bioprinting has been used widely in tissue engineering applications [147]. Examples of generated tissues include functional, synchronously beating cardiac tissues grown from embryonic cardiac and endothelial cells [154]; mammalian bladder tissue [155]; vascular structures from porcine aortic smooth muscle cells [150]; and human skin models from keratinocyte and fibroblast layers in collagen [156]. Alternatively, bioprinters could also be used to control the placement of growth factors in cellular microenvironments. This approach was applied to direct the differentiation of stem cells into muscle and bone cells [157] and morphing of osteoblasts into bone cells [158].

\section{Conclusions and Outlook}

Advantages of using hydrogels for cell and tissue studies include their cytocompatibility, degradability, and porosity. In addition, hydrogels are readily compatible with microscale fabrication techniques, such as soft and photo-lithography, flow focusing, electrospinning, bioprinting and others. These techniques allow for highly accurate and precise patterning of hydrogel structures and cell encapsulation. Some of the methods presented here are better suitable for certain applications than others. For example, soft and photolithography processes are amenable to generating microscale scaffolds on the order of several hundred $\mu \mathrm{m}$, while structures capable of encapsulating single cells are more easily generated using flow focusing inside microfluidic devices. Also, good large-scale spatial organization of the scaffolds can be easily achieved using soft lithography, photolithography and bioprinting, while electro-spinning and -spraying lead to random positioning of the fabricated structures. Thus, the choice of the microscale technique to generate cell-containing hydrogel particles largely depends on whether single-cell and screening experiments are to be conducted and whether the goal is to assemble tissues in vitro from the bottom up or engineer it from the top down. In the first case, small, spatially controlled features are desired, while in the second case larger structures, including hydrogel fibers, can be useful. Additionally, the type of cell used is also important: Certain cells, e.g., primary cardiomyocytes, are more sensitive to their environment (temperature, shear stress, $\mathrm{pH}$ ) than fibroblasts, making them less compatible with microfluidic methods than with soft and photolithography.

However, all presented techniques enable the generation of well-controlled tissue constructs for drug screening, (stem-)cell studies, and potentially growth of individual organ tissues. As the ultimate goal, the organ-on-a-chip concept has already been utilized for mimicking cardiac [159] and lung tissues [160], the gastrointestinal villi [161], and even for growth and successful implantation of a human bladder [155]. In the future, cell-containing microgels will likely continue to be employed in tissue engineering applications. In addition, they could potentially be useful for drug screening and therapeutic studies. Future research endeavors will also likely depend on the development of a high-throughput platform for generating microscale cell-encapsulating hydrogel structures. Ideally, such a platform would be compatible with a range of hydrogel materials and cells, it would offer a stable fabrication system, and be capable of generating particles of different sizes and shapes. This level of versatility is currently only offered by bioprinting approaches, as they enable generation of any preprogrammed 3D shape. 


\section{Acknowledgments}

This paper was supported by the following agencies: National Science Foundation (DMR0847287), National Institutes of Health (EB008392; DE019024; HL099073; AR057837; HL092836), Office of Naval Research, Institute for Soldier Nanotechnology, US Army Corps of Engineers, and the U.S. Army Research Office under contract W911NF-07-D-0004. JO was supported by a Postdoctoral Fellowship from Innovative Medical Tech Co.

\section{References}

1. Bonassar, L.J.; Vacanti, C.A. Tissue engineering: The first decade and beyond. J. Cell. Biochem. 1998, 30-31, 297-303.

2. Nichol, J.; Khademhosseini, A. Modular tissue engineering: Engineering biological tissues from the bottom up. Soft Matter 2009, 5, 1312-1319.

3. Khademhosseini, A.; Langer, R.; Borenstein, J.; Vacanti, J.P. Microscale technologies for tissue engineering and biology. Proc. Natl. Acad. Sci. USA 2006, 103, 2480-2487.

4. Khademhosseini, A.; Vacanti, J.; Langer, R. Tissue engineering: Next generation tissue constructs and challenges to clinical practice. Sci. Am. 2009, 300, 64-71.

5. Brandl, F.; Sommer, F.; Goepferich, A. Rational design of hydrogels for tissue engineering: Impact of physical factors on cell behavior. Biomaterials 2007, 28, 134-146.

6. Inamdar, N.K.; Borenstein, J.T. Microfluidic cell culture models for tissue engineering. Curr. Opin. Biotechnol. 2011, 22, 1-9.

7. Kaji, H.; Camci-Unal, G.; Langer, R.; Khademhosseini, A. Engineering systems for the generation of patterned co-cultures for controlling cell-cell interactions. Biochim. Biophys. Acta 2011, 1810, 239-250.

8. Park, H.; Cannizzaro, C.; Vunjak-Novakovic, G.; Langer, R.; Vacanti, C.A.; Farokhzad, O.C. Nanofabrication and microfabrication of functional materials for tissue engineering. Tissue Eng. 2007, 13, 1867-1877.

9. Brouzesa, E.; Medkova, M.; Savenelli, N.; Marran, D.; Twardowski, M.; Hutchison, J.B.; Rothberg, J.M.; Link, D.R.; Perrimon, N.; Samuels, M.L. Droplet microfluidic technology for single-cell highthroughput screening. Proc. Natl. Acad. Sci. USA. 2009, 106, 14195-14200.

10. Clausell-Tormos, J.; Lieber, D.; Baret, J.C.; El-Harrak, A.; Miller, O.J.; Frenz, L.; Blouwolff, J.; Humphry, K.J.; Köster, S.; Duan, H.; Holtze, C.; Weitz, D.A.; Griffiths, A.D.; Merten, C.A. Droplet-based microfluidic platforms for the encapsulation and screening of mammalian cells and multicellular organisms. Chem. Biol. 2008, 15, 427-437.

11. Jayasinghe, S.N.; Irvine, S.; McEwan, J.R. Cell electrospinning highly concentrated cellular suspensions containing primary living organisms into cell-bearing threads and scaffolds. Nanomedicine 2007, 2, 555-567.

12. Townsend-Nicholson, A.; Jayasinghe, S.N. Cell electrospinning: A unique biotechnique for encapsulating living organisms for generating active biological microthreads/scaffolds. Biomacromolecules 2006, 7, 3364-3369. 
13. Sant, S.; Hwang, C.; Lee, S.; Khademhosseini, A. Hybrid PGS-PCL microfibrous scaffolds with improved mechanical and biological properties. J. Tissue Eng. Regen. Med. 2011, 5, 283-291.

14. Abeyewickreme, A.; Kwok, A.; McEwan, J.R.; Jayasinghe, S.N. Bio-electrospraying embryonic stem cells: Interrogating cellular viability and pluripotency. Integr. Biol. 2009, 1, 160-166.

15. Liu, V.A.; Bhatia, S.N. Three-Dimensional Photopatterning of Hydrogels Containing Living Cells. Biomed. Microdevices 2002, 4, 257-266.

16. Kim, Y.S.; Suh, K.Y.; Lee, H.H. Fabrication of three-dimensional microstructures by soft molding. Appl. Phys. Lett. 2001, 79, 2285-2287.

17. Whitesides, G.M.; Ostuni, E.; Takayama, S.; Jiang, X.; Ingber, D. Soft lithography in biology and biochemistry. Annu. Rev. Biomed. Eng. 2001, 3, 335-373.

18. Nichol, J.W.; Koshy, S.T.; Bae, H.; Hwang, C.M.; Yamanlar, S.; Khademhosseini, A. Cell-laden microengineered gelatin methacrylate hydrogels. Biomaterials 2010, 31, 5536-5544.

19. Tekin, H.; Anaya, M.; Brigham, M.D.; Naumann, C.; Langer, R.; Khademhosseini, A. Stimuli-responsive microwells for formation and retrieval of cell aggregates. Lab Chip 2010, 10, 2411-2418.

20. Mironov, V.; Reis, N.; Derby, B. Bioprinting: A Beginning. Tissue Eng. 2006, 12, 632-634.

21. Mironov, V.; Prestwich, G.; Forgacs, G. Bioprinting living structures. J. Mater. Chem. 2007, 17, 2054-2060.

22. Jakab, K.; Damon, B.; Neagu, A.; Kachurin, A.; Forgacs, G. Three-dimensional tissue constructs built by bioprinting. Biorheology 2006, 43, 509-513.

23. Karoly, J.; Cyrille, N.; Francoise, M.; Keith, M.; Gordana, V.-N.; Gabor, F. Tissue engineering by self-assembly and bio-printing of living cells. Biofabrication 2010, 2, 022001.

24. Yanagawa, F.; Kaji, H.; Jang, Y.-H.; Bae, H.; Du, Y.; Fukuda, J.; Qi, H.; Khademhosseini, A. Directed assembly of cell-laden microgels for building porous three-dimensional tissue constructs. J. Biomed. Mater. Res. A 2011, 97, 93-102.

25. Maquet, V.; Martin, D.; Scholtes, F.; Franzen, R.; Schoenen, J.; Moonen, G.; Jerome, R. Poly(d,l-lactide) foams modified by poly(ethylene oxide)-block-poly(d,l-lactide) copolymers and a-FGF: In vitro and in vivo evaluation for spinal cord regeneration. Biomaterials 2001, 22, 1137-1146.

26. Ambre, A.H.; Katti, K.S.; Katti, D.R. Nanoclay based composite scaffolds for bone tissue engineering applications. J. Nanotechnol. Eng. Med. 2010, 1, 031013:1-031013:9.

27. Khademhosseini, A.; Eng, G.; Yeh, J.; Fukuda, J.; Blumling, J.; Langer, R.; Burdick, J.A. Micromolding of photocrosslinkable hyaluronic acid for cell encapsulation and entrapment. $J$. Biomed. Mater. Res. A 2006, 79, 522-532.

28. Xiao, W.; He, J.; Nichol, J.W.; Wang, L.; Hutson, C.B.; Wang, B.; Du, Y.; Fan, H.; Khademhosseini, A. Synthesis and characterization of photocrosslinkable gelatin and silk fibroin interpenetrating polymer network hydrogels. Acta Biomater. 2011, 7, 2384-2393.

29. Jeon, O.; Bouhadir, K.H.; Mansour, J.M.; Alsberg, E. Photocrosslinked alginate hydrogels with tunable biodegradation rates and mechanical properties. Biomaterials 2009, 30, 2724-2734.

30. Ifkovits, J.L.; Burdick, J.A. Review: Photopolymerizable and degradable biomaterials for tissue engineering applications. Tissue Eng. 2007, 13, 2369-2385. 
31. Hutson, C.B.; Nichol, J.W.; Aubin, H.; Bae, H.; Yamanlar, S.; Al-Haque, S.; Koshy, S.T.; Khademhosseini, A. Synthesis and characterization of tunable poly(ethylene glycol): Gelatin methacrylate composite hydrogels. Tissue Eng. A 2011, 17, 1713-1723.

32. Cruise, G.M.; Scharp, D.S.; Hubbell, J.A. Characterization of permeability and network structure of interfacially photopolymerized poly(ethylene glycol) diacrylate hydrogels. Biomaterials 1998, 19, 1287-1294.

33. Chan-Park, M.B.; Yan, Y.; Neo, W.K.; Zhou, W.; Zhang, J.; Yue, C.Y. Fabrication of high aspect ratio poly(ethylene glycol)-containing microstructures by UV embossing. Langmuir 2003, 19, 4371-4380.

34. Revzin, A.; Tompkins, R.G.; Toner, M. Surface engineering with poly(ethylene glycol) photolithography to create high-density cell arrays on glass. Langmuir 2003, 19, 9855-9862.

35. Khademhosseini, A.; Yeh, J.; Jon, S.; Eng, G.; Suh, K.Y.; Burdick, J.A.; Langer, R. Molded polyethylene glycol microstructures for capturing cells within microfluidic channels. Lab Chip 2004, 4, 425-430.

36. Bahney, C.S.; Lujan, T.J.; Hsu, C.W.; Bottlang, M.; West, J.L.; Johnstone, B. Visible light photoinitiation of mesenchymal stem cell-laden bioresponsive hydrogels. Eur. Cells Mater. 2011, 22, 43-55.

37. Nguyen, K.T.; West, J.L. Photopolymerizable hydrogels for tissue engineering applications. Biomaterials 2002, 23, 4307-4314.

38. Dare, E.V.; Griffith, M.; Poitras, P.; Kaupp, J.A.; Waldman, S.D.; Carlsson, D.J.; Dervin, G.; Mayoux, C.; Hincke, M.T. Genipin cross-linked fibrin hydrogels for in vitro human articular cartilage tissue-engineered regeneration. Cells Tissues Organs 2009, 190, 313-325.

39. Bigi, A.; Cojazzi, G.; Panzavolta, S.; Roveri, N.; Rubini, K. Stabilization of gelatin films by crosslinking with genipin. Biomaterials 2002, 23, 4827-4832.

40. Thalmann, C.; Lötzbeyer, T. Enzymatic cross-linking of proteins with tyrosinase. Eur. Food Res. Technol. 2002, 214, 276-281.

41. Sanborn, T.J.; Messersmith, P.B.; Barron, A.E. In situ crosslinking of a biomimetic peptide-PEG hydrogel via thermally triggered activation of factor XIII. Biomaterials 2002, 23, 2703-2710.

42. Davis, N.E.; Ding, S.; Forster, R.E.; Pinkas, D.M.; Barron, A.E. Modular enzymatically crosslinked protein polymer hydrogels for in situ gelation. Biomaterials 2010, 31, 7288-7297.

43. Kuo, C.K.; Ma, P.X. Ionically crosslinked alginate hydrogels as scaffolds for tissue engineering: Part 1. Structure, gelation rate and mechanical properties. Biomaterials 2001, 22, 511-521.

44. Hennink, W.E.; van Nostrum, C.F. Novel crosslinking methods to design hydrogels. Adv. Drug Deliv. Rev. 2002, 54, 13-36.

45. Gohil, J.; Bhattacharya, A.; Ray, P. Studies on the crosslinking of poly (vinyl alcohol). J. Polym. Res. 2006, 13, 161-169.

46. Maolin, Z.; Ning, L.; Jun, L.; Min, Y.; Jiuqiang, L.; Hongfei, H. Radiation preparation of PVA-g-NIPAAm in a homogeneous system and its application in controlled release. Radiat. Phys. Chem. 2000, 57, 481-484.

47. Li, S.; Molina, I.; Martinez, M.B.; Vert, M. Hydrolytic and enzymatic degradations of physically crosslinked hydrogels prepared from PLA/PEO/PLA triblock copolymers. J. Mater. Sci. Mater. Med. 2002, 13, 81-86. 
48. Levesque, S.G.; Shoichet, M.S. Synthesis of enzyme-degradable, peptide-cross-linked dextran hydrogels. Bioconjug. Chem. 2007, 18, 874-885.

49. Lee, K.Y.; Bouhadir, K.H.; Mooney, D.J. Controlled degradation of hydrogels using multi-functional cross-linking molecules. Biomaterials 2004, 25, 2461-2466.

50. Cha, C.; Kohman, R.H.; Kong, H. Biodegradable polymer crosslinker: Independent control of stiffness, toughness, and hydrogel degradation rate. Adv. Funct. Mater. 2009, 19, 3056-3062.

51. Bastioli, C. Handbook of Biodegradable Polymers; Rapra Technology Limited: Shawbury, UK, 2005.

52. Nicodemus, G.D.; Bryant, S.J. Cell encapsulation in biodegradable hydrogels for tissue engineering applications. Tissue Eng. B Rev. 2008, 14, 149-165.

53. Wu, D.-Q.; Sun, Y.-X.; Xu, X.-D.; Cheng, S.-X.; Zhang, X.-Z.; Zhuo, R.-X. Biodegradable and pH-sensitive hydrogels for cell encapsulation and controlled drug release. Biomacromolecules 2008, 9, 1155-1162.

54. Ishihara, M.; Obara, K.; Ishizuka, T.; Fujita, M.; Sato, M.; Masuoka, K.; Saito, Y.; Yura, H.; Matsui, T.; Hattori, H.; Kikuchi, M.; Kurita, A. Controlled release of fibroblast growth factors and heparin from photocrosslinked chitosan hydrogels and subsequent effect on in vivo vascularization. J. Biomed. Mater. Res. A 2003, 64A, 551-559.

55. Slaughter, B.V.; Khurshid, S.S.; Fisher, O.Z.; Khademhosseini, A.; Peppas, N.A. Hydrogels in regenerative medicine. Adv. Mater. 2009, 21, 3307-3329.

56. Verma, S.; Garkhal, K.; Mittal, A.; Kumar, N. Biodegradable polymers for emerging clinical use in tissue engineering. In Biodegradable Polymers in Clinical Use and Clinical Development; Domb, A.J., Kumar, N., Ezra, A., Eds.; John Wiley \& Sons, Inc.: Hoboken, NJ, USA, 2011; pp. 565-629.

57. Mufamadi, M.S.; Pillay, V.; Choonara, Y.E.; du Toit, L.C.; Modi, G.; Naidoo, D.; Ndesendo, V.M.K. A review on composite liposomal technologies for specialized drug delivery. J. Drug Deliv. 2011, 2011, 939851:1-939851:19.

58. Vorhies, J.S.; Nemunaitis, J.J. Synthetic vs. natural/biodegradable polymers for delivery of shrna-based cancer therapies. Methods Mol. Biol. 2008, 480, 11-29.

59. Nuttelman, C.R.; Henry, S.M.; Anseth, K.S. Synthesis and characterization of photocrosslinkable, degradable poly(vinyl alcohol)-based tissue engineering scaffolds. Biomaterials 2002, 23, 3617-3626.

60. Lutolf, M.P.; Raeber, G.P.; Zisch, A.H.; Tirelli, N.; Hubbell, J.A. Cell-responsive synthetic hydrogels. Adv. Mater. 2003, 15, 888-892.

61. Schmedlen, R.H.; Masters, K.S.; West, J.L. Photocrosslinkable polyvinyl alcohol hydrogels that can be modified with cell adhesion peptides for use in tissue engineering. Biomaterials 2002, 23, 4325-4332.

62. Xia, Y.; Whitesides, G.M. Soft Lithography. Angew. Chem. Int. Ed. 1998, 37, 550-575.

63. Xia, Y.; McClelland, J.J.; Gupta, R.; Qin, D.; Zhao, X.-M.; Sohn, L.L.; Celotta, R.J.; Whitesides, G.M. Replica molding using polymeric materials: A practical step toward nanomanufacturing. Adv. Mater. 1997, 9, 147-149.

64. Zhang, Y.; Lo, C.-W.; Taylor, J.A.; Yang, S. Replica molding of high-aspect-ratio polymeric nanopillar arrays with high fidelity. Langmuir 2006, 22, 8595-8601. 
65. Teruo, F. PDMS-based microfluidic devices for biomedical applications. Microelectron. Eng. 2002, 61-62, 907-914.

66. Regehr, K.J.; Domenech, M.; Koepsel, J.T.; Carver, K.C.; Ellison-Zelski, S.J.; Murphy, W.L.; Schuler, L.A.; Alarid, E.T.; Beebe, D.J. Biological implications of polydimethylsiloxane-based microfluidic cell culture. Lab Chip 2009, 9, 2132-2139.

67. Moeller, H.-C.; Mian, M.K.; Shrivastava, S.; Chung, B.; Khademhosseini, A. A microwell array system for stem cell culture. Biomaterials 2008, 29, 752-763.

68. Zhao, X.-M.; Xia, Y.; Whitesides, G.M. Fabrication of three-dimensional micro-structures: Microtransfer molding. Adv. Mater. 1996, 8, 837-840.

69. Tekin, H.; Tsinman, T.; Sanchez, J.G.; Jones, B.J.; Camci-Unal, G.; Nichol, J.W.; Langer, R.; Khademhosseini, A. Responsive micromolds for sequential patterning of hydrogel microstructures. J. Am. Chem. Soc. 2011, 133, 12944-12947.

70. Tekin, H.; Sanchez, J.G.; Tsinman, T.; Langer, R.; Khademhosseini, A. Thermoresponsive platforms for tissue engineering and regenerative medicine. AIChE J. 2011, 57, 3249-3258.

71. Chu, M.K.L.; Chen, J.; Gordijo, C.R.; Chiang, S.; Ivovic, A.; Koulajian, K.; Giacca, A.; Wu, X.Y.; Sun, Y. In vitro and in vivo testing of glucose-responsive insulin-delivery microdevices in diabetic rats. Lab Chip 2012, 12, 2533-2539.

72. Kim, E.; Xia, Y.; Whitesides, G.M. Micromolding in capillaries: Applications in materials science. J. Am. Chem. Soc. 1996, 118, 5722-5731.

73. Blümel, A.; Klug, A.; Eder, S.; Scherf, U.; Moderegger, E.; List, E.J.W. Micromolding in capillaries and microtransfer printing of silver nanoparticles as soft-lithographic approach for the fabrication of source/drain electrodes in organic field-effect transistors. Org. Electron. 2007, 8, 389-395.

74. Zhao, X.-M.; Stoddart, A.; Smith, S.P.; Kim, E.; Xia, Y.; Prentiss, M.; Whitesides, G.M. Fabrication of single-mode polymeric waveguides using micromolding in capillaries. Adv. Mater. 1996, 8, 420-424.

75. Delamarche, E.; Bernard, A.; Schmid, H.; Michel, B.; Biebuyck, H. Patterned delivery of immunoglobulins to surfaces using microfluidic networks. Science 1997, 276, 779-781.

76. Ling, Y.; Rubin, J.; Deng, Y.; Huang, C.; Demirci, U.; Karp, J.M.; Khademhosseini, A. A cell-laden microfluidic hydrogel. Lab Chip 2007, 7, 756-762.

77. Du, Y.; Ghodousi, M.; Lo, E.; Vidula, M.K.; Emiroglu, O.; Khademhosseini, A. Surface-directed assembly of cell-laden microgels. Biotechnol. Bioeng. 2009, 105, 655-662.

78. Fisher, J.P.; Dean, D.; Engel, P.S.; Mikos, A.G. Photoinitiated polymerization of biomaterials. Mater. Res. 2001, 31, 171-181.

79. Yang, S.; Ford, J.; Ruengruglikit, C.; Huang, Q.; Aizenberg, J. Synthesis of photoacid crosslinkable hydrogels for the fabrication of soft, biomimetic microlens arrays. J. Mater. Chem. 2005, 15, 4200-4202.

80. Maldovan, M.; Thomas, E.L. Periodic Materials and Interference Lithography; Wiley: Weinheim, Germany, 2009.

81. Lin, C.-C.; Raza, A.; Shih, H. PEG hydrogels formed by thiol-ene photo-click chemistry and their effect on the formation and recovery of insulin-secreting cell spheroids. Biomaterials 2011, 32, 9685-9695. 
82. Albrecht, D.R.; Tsang, V.L.; Sah, R.L.; Bhatia, S.N. Photo- and electropatterning of hydrogel-encapsulated living cell arrays. Lab Chip 2005, 5, 111-118.

83. Bencherif, S.A.; Siegwart, D.J.; Srinivasan, A.; Horkay, F.; Hollinger, J.O.; Washburn, N.R.; Matyjaszewski, K. Nanostructured hybrid hydrogels prepared by a combination of atom transfer radical polymerizaiton and free radical polymerization. Biomaterials 2009, 30, 5270-5278.

84. Park, Y.D.; Tirelli, N.; Hubbell, J.A. Photopolymerized hyaluronic acid-based hydrogels and interpenetrating networks. Biomaterials 2003, 24, 893-900.

85. Ng, L.-T.; Jönsson, S.; Swami, S.; Lindgren, K. Synthesis of hydrogel for drug delivery studies utilizing photoinitiator-free photopolymerization based on the donor/acceptor pair, $N$-vinylpyrrolidinone and hydroxypentyl maleimide. Polym. Int. 2002, 51, 1398-1403.

86. Dendukuri, D.; Gu, S.S.; Pregibon, D.C.; Hatton, T.A.; Doyle, P.S. Stop-flow lithography in a microfluidic device. Lab Chip 2007, 7, 818-828.

87. Kasko, A.M.; Wong, D.Y. Two-photon lithography in the future of cell-based therapeutics and regenerative medicine: A review of techniques for hydrogel patterning and controlled release. Future Med. Chem. 2010, 2, 1669-1680.

88. Jeon, S.; Malyarchuk, V.; Rogers, J.A.; Wiederrecht, G.P. Fabricating three dimensional nanostructures using two photon lithography in a single exposure step. Opt. Express 2006, 14, 2300-2308.

89. Lee, S.-H.; Moon, J.J.; West, J.L. Three-dimensional micropatterning of bioactive hydrogels via two-photon laser scanning photolithography for guided 3D cell migration. Biomaterials 2008, 29, 2962-2968.

90. Squires, T.; Quake, S. Microfluidics: Fluid physics at the nanoliter scale. Rev. Mod. Phys. 2005, 77, 977-1026.

91. Whitesides, G.M. The origins and the future of microfluidics. Nature 2006, 442, 368-373.

92. Flaim, C.J.; Chien, S.; Bhatia, S.N. An extracellular matrix microarray for probing cellular differentiation. Nat. Methods 2005, 2, 119-125.

93. Anderson, D.G.; Levenberg, S.; Langer, R. Nanoliter-scale synthesis of arrayed biomaterials and application to human embryonic stem cells. Nat. biotechnol. 2004, 22, 863-866.

94. Young, E.W.; Beebe, D.J. Fundamentals of microfluidic cell culture in controlled microenvironments. Chem. Soc. Rev. 2010, 39, 1036-1048.

95. Lim, J.Y.; Kim, W.H.; Kim, J.; Park, S.I. Involvement of TGF-beta1 signaling in cardiomyocyte differentiation from P19CL6 cells. Mol. cells 2007, 24, 431-436.

96. Atencia, J.; Beebe, D.J. Controlled microfluidic interfaces. Nature 2005, 437, 648-655.

97. Whitesides, G.M.; Stroock, A.D. Flexible methods for mircofluidics. Phys. Today 2001, 54, 42-48.

98. Wu, M.-H.; Huang, S.-B.; Lee, G.-B. Microfluidic cell culture systems for drug research. Lab Chip 2010, 10, 939-956.

99. Dittrich, P.S.; Manz, A. Lab-on-a-chip: microfluidics in drug discovery. Nat. Rev. Drug Discov. 2006, 5, 210-218.

100. Yeo, L.Y.; Chang, H.-C.; Chan, P.P.Y.; Friend, J.R. Microfluidic devices for bioapplications. Small 2011, 7, 12-48. 
101. Gupta, K.; Kim, D.-H.; Ellison, D.; Smith, C.; Kundu, A.; Tuan, J.; Suh, K.-Y.; Levchenko, A. Lab-on-a-chip devices as an emerging platform for stem cell biology. Lab Chip 2010, 10, 2019-2031.

102. Van Noort, D.; Ong, S.M.; Zhang, C.; Zhang, S.; Arooz, T.; Yu, H. Stem cells in microfluidics. Biotechnol. Progr. 2009, 25, 52-60.

103. Wlodkowic, D.; Cooper, J.M. Tumors on chips: Oncology meets microfluidics. Curr. Opin. Chem. Biol. 2010, 14, 556-567.

104. Chung, S.; Sudo, R.; Vickerman, V.; Zervantonakis, I.K.; Kamm, R.D. Microfluidic platforms for studies of angiogenesis, cell migration, and cell-cell interactions. Annu. Biomed. Eng. 2010, 38, 1164-1177.

105. Zervantonakis, I.K.; Kothapalli, C.R.; Chung, S.; Sudo, R.; Kamm, R.D. Microfluidic devices for studying heterotypic cell-cell interactions and tissue specimen cultures under controlled microenvironments. Biomicrofluidics 2011, 5, 013406.

106. Ahmed, T.; Shimizu, T.S.; Stocker, R. Microfluidics for bacterial chemotaxis. Integr. Biol. 2010, 2, 604-629.

107. Ziolkowska, K.; Kwapiszewski, R.; Brzozka, Z. Microfluidic devices as tools for mimicking the in vivo environment. New J. Chem. 2011, 35, 979-990.

108. Paguirigan, A.L.; Beebe, D.J. From the cellular perspective: Exploring differences in the cellular baseline in macroscale and microfluidic cultures. Integr. Biol. 2009, 1, 182-195.

109. Meyvantsson, I.; Beebe, D.J. Cell culture models in microfluidic systems. Annu. Rev. Anal. Chem. 2008, 1, 423-449.

110. Le Gac, S.; van den Berg, A. Single cells as experimentation units in lab-on-a-chip devices. Trends Biotechnol. 2010, 28, 55-62.

111. Domansky, K.; Inman, W.; Serdy, J.; Dash, A.; Lim, M.H.M.; Griffith, L.G. Perfused multiwell plate for 3D liver tissue engineering. Lab Chip 2010, 10, 51-58.

112. Sim, W.Y.; Park, S.-W.; Park, S.H.; Min, B.H.; Park, S.R.; Yang, S.S. A pneumatic micro cell chip for the differentiation of human mesenchymal stem cells under mechanical stimulation. Lab Chip 2007, 7, 1775-1782.

113. Capron, I.; Costeux, S.; Djabourov, M. Water in water emulsions: Phase separation and rheology of biopolymer solutions. Rheol. Acta 2001, 40, 441-456.

114. Stenekes, R.J.H.; Franssen, O.; Bommel, E.M.G.v.; Crommelin, D.J.A.; Hennink, W.E. The use of aqueous PEG/dextran phase separation for the preparation of dextran microspheres. Int. J. Pharm. 1999, 183, 29-32.

115. Yasukawa, M.; Kamio, E.; Ono, T. Monodisperse water-in-water-in-oil emulsion droplets. ChemPhysChem. 2011, 12, 263-266.

116. Shintaku, H.; Kuwabara, T.; Kawano, S.; Suzuki, T.; Kanno, I.; Kotera, H. Micro cell encapsulation and its hydrogel-beads production using microfluidic device. Microsyst. Technol. 2007, 13, 951-958.

117. Haeberle, S.; Naegele, L.; Burger, R.; Stetten, F.V.; Zengerle, R.; Ducre'e, J. Alginate bead fabrication and encapsulation of living cells under centrifugally induced artificial gravity conditions. J. Microencapsul. 2008, 25, 267-274. 
118. Nisisako, T.; Torii, T.; Takahashi, T.; Takizawa, Y. Synthesis of monodisperse bicolored janus particles with electrical anisotropy using a microfluidic co-flow system. Adv. Mater. 2006, 18, 1152-1156.

119. Prasad, N.; Perumal, J.; Choi, C.-H.; Lee, C.-S.; Kim, D.-P. Generation of monodisperse inorganic-organic janus microspheres in a microfluidic device. Adv. Funct. Mater. 2009, 19, 1656-1662.

120. Seiffert, S. Functional microgels tailored by droplet-based microfluidics. Macromol. Rapid Commun. 2011, 32, 1600-1609.

121. Seiffert, S.; Romanowsky, M.B.; Weitz, D.A. Janus microgels produced from functional precursor polymers. Langmuir 2010, 26, 14842-14847.

122. Abate, A.R.; Kutsovsky, M.; Seiffert, S.; Windbergs, M.; Pinto, L.F.V.; Rotem, A.; Utada, A.S.; Weitz, D.A. Synthesis of monodisperse microparticles from non-newtonian polymer solutions with microfluidic devices. Adv. Mater. 2011, 23, 1757-1760.

123. Chen, C.-H.; Abate, A.R.; Lee, D.; Terentjev, E.M.; Weitz, D.A. Microfluidic assembly of magnetic hydrogel particles with uniformly anisotropic structure. Adv. Mater. 2009, 21, 3201-3204.

124. Utada, A.S.; Chu, L.-Y.; Fernandez-Nieves, A.; Link, D.R.; Holtze, C.; Weitz, D.A. Dripping, jetting, drops, and wetting: The magic of microfluidics. MRS Bull. 2007, 32, 702-708.

125. Chu, L.-Y.; Utada, A.S.; Shah, R.K.; Kim, J.-W.; Weitz, D.A. Controllable monodisperse multiple emulsions. Angew. Chem. Int. Ed. 2007, 46, 8970-8974.

126. Lee, K.G.; Park, T.J.; Soo, S.Y.; Wang, K.W.; Kim, B.I.; Park, J.H.; Lee, C.-S.; Kim, D.H.; Lee, S.J. Synthesis and utilization of E. coli-encapsulated PEG-based microdroplet using a microfluidic chip for biological application. Biotechnol. Bioeng. 2010, 107, 747-751.

127. Franco, C.L.; Price, J.; West, J.L. Development and optimization of a dual-photoinitiator, emulsion-based technique for rapid generation of cell-laden hydrogel microspheres. Acta Biomater. 2011, 7, 3267-3276.

128. Koh, W.-G.; Pishko, M.V. Fabrication of cell-containing hydrogel microstructures inside microfluidic devices that can be used as cell-based biosensors. Anal. Bioanal. Chem. 2006, 385, 1389-1397.

129. Tan, W.-H.; Takeuchi, S. Monodisperse alginate hydrogel microbeads for cell encapsulation. Adv. Mater. 2007, 19, 2696-2701.

130. Vijayakumar, K.; Gulati, S.; deMello, A.J.; Edel, J.B. Rapid cell extraction in aqueous two-phase microdroplet systems. Chem. Sci. 2010, 1, 447-452.

131. Um, E.; Lee, D.-S.; Pyo, H.-B.; Park, J.-K. Continuous generation of hydrogel beads and encapsulation of biological materials using a microfluidic droplet-merging channel. Microfluid. Nanofluid. 2008, 5, 541-549.

132. Tsuda, Y.; Morimoto, Y.; Takeuchi, S. Monodisperse cell-encapsulating peptide microgel beads for 3D cell culture. Langmuir 2010, 26, 2645-2649.

133. Cordero, M.L.; Gallaire, F.; Baroud, C.N. Quantitative analysis of the dripping and jetting regimes in co-fowing capillary jets. Phys. Fluids 2011, 23, 094111.

134. Steinbacher, J.L.; McQuade, D.T. Polymer chemistry in flow: New polymers, beads, capsules, and fibers. J. Polym. Chem. A 2006, 44, 6505-6533. 
135. Hu, M.; Deng, R.; Schumacher, K.M.; Kurisawa, m.; Ye, H.; Purnamawati, K.; Ying, J.Y. Hydrodynamic spinning of hydrogel fibers. Biomaterials 2009, 31, 863-869.

136. Kang, E.; Jeong, G.S.; Choi, Y.Y.; Lee, K.H.; Khademhosseini, A.; Lee, S.-H. Digitally tunable physicochemical coding of material composition and topography in continuous microfibres. Nat. Mater. 2011, 10, 877-883.

137. Yeh, C.-H.; Lin, P.-W.; Lin, Y.-C. Chitosan microfiber fabrication using a microfluidic chip and its application to cell cultures. Microfluid. Nanofluid. 2010, 8, 115-121.

138. Honda, T.; Miyazaki, M.; Nakamura, H.; Maeda, H. Controllable polymerization of $N$-carboxy anhydrides in a microreaction system. Lab Chip 2005, 5, 812-818.

139. Ramakrishna, S. An Introduction to Electrospinning and Nanofibers; World Scientific Publishing, SI: Singapore, 2005.

140. Hong, J.; deMello, A.J.; Jayasinghe, S.N. Bio-electrospraying and droplet-based microfluidics: Control of cell numbers within living residues. Biomed. Mater. 2010, 5, 021001.

141. Ward, E.; Chan, E.; Gustafson, K.; Jayasinghe, S.N. Combining bio-electrospraying with gene therapy: A novel biotechnique for the delivery of genetic material via living cells. Analyst 2010, 135, 1042-1049.

142. Klein, S.; Kuhn, J.; Avrahami, R.; Tarre, S.; Beliavski, M.; Green, M.; Zussman, E. Encapsulation of bacterial cells in electrospun microtubes. Biomacromolecules 2009, 10, 1751-1756.

143. Boland, T.; Tao, X.; Damon, B.J.; Manley, B.; Kesari, P.; Jalota, S.; Bhaduri, S. Drop-on-demand printing of cells and materials for designer tissue constructs. Mater. Sci. Eng. C 2007, 27, 372-376.

144. Baudoin, R.; Corlu, A.; Griscom, L.; Legallais, C.; Leclerc, E. Trends in the development of microfluidic cell biochips for in vitro hepatotoxicity. Toxicol. In Vitro 2007, 21, 535-544.

145. Ghaemmaghami, A.M.; Hancock, M.J.; Harrington, H.; Kaji, H.; Khademhosseini, A. Biomimetic tissues on a chip for drug discovery. Drug Discov. Today 2011, 17, 173-181.

146. Wang, X.; Yan, Y.; Zhang, R. Recent trends and challenges in complex organ manufacturing. Tissue Eng. B Rev. 2010, 16, 189-197.

147. Mironov, V.; Kasyanov, V.; Markwald, R.R. Organ printing: From bioprinter to organ biofabrication line. Curr. Opin. Biotechnol. 2011, 22, 667-673.

148. Skardal, A.; Zhang, J.; McCoard, L.; Xu, X.; Oottamasathien, S.; Prestwich, G.D. Photocrosslinkable hyaluronan-gelatin hydrogels for two-step bioprinting. Tissue Eng. A 2010, 16, 2675-2685.

149. Chaudhuri, J.; Al-Rubeai, M. Bioreactors for Tissue Engineering: Principles, Design and Operation; Springer: Dordrecht, The Netherlands, 2005.

150. Norotte, C.; Marga, F.S.; Niklason, L.E.; Forgacs, G. Scaffold-free vascular tissue engineering using bioprinting. Biomaterials 2009, 30, 5910-5917.

151. Derby, B. Bioprinting: Inkjet printing proteins and hybrid cell-containing materials and structures. J. Mater. Chem. 2008, 18, 5717-5721.

152. Nakamura, M.; Kobayashi, A.; Takagi, F.; Watanabe, A.; Hiruma, Y.; Ohuchi, K.; Iwasaki, Y.; Horie, M.; Morita, I.; Takatani, S. Biocompatible inkjet printing technique for designed seeding of individual living cells. Tissue Eng. 2005, 11, 1658-1666. 
153. Neagu, A.; Jakab, K.; Jamison, R.; Forgacs, G. Role of physical mechanisms in biological self-organization. Phys. Rev. Lett. 2005, 95, 178104:1-178104:4.

154. Jakab, K.; Norotte, C.; Damon, B.; Marga, F.; Neagu, A.; Besch-Williford, C.L.; Kachurin, A.; Church, K.H.; Park, H.; Mironov, V.; Markwald, R.; Vunjak-Novakovic, G.; Forgacs, G. Tissue engineering by self-assembly of cells printed into topologically defined structures. Tissue Eng. A 2008, 14, 413-421.

155. Oberpenning, F.; Meng, J.; Yoo, J.J.; Atala, A. De novo reconstitution of a functional mammalian urinary bladder by tissue engineering. Nat. Biotechnol. 1999, 17, 149-155.

156. Lee, W.; Debasitis, J.C.; Lee, V.K.; Lee, J.-H.; Fischer, K.; Edminster, K.; Park, J.-K.; Yoo, S.-S. Multi-layered culture of human skin fibroblasts and keratinocytes through three-dimensional freeform fabrication. Biomaterials 2009, 30, 1587-1595.

157. Phillippi, J.A.; Miller, E.; Weiss, L.; Huard, J.; Waggoner, A.; Campbell, P. Microenvironments engineered by inkjet bioprinting spatially direct adult stem cells toward muscle- and bone-like subpopulations. Stem Cells 2008, 26, 127-134.

158. Cooper, G.M.; Miller, E.D.; DeCesare, G.E.; Usas, A.; Lensie, E.L.; Bykowski, M.R.; Huard, J.; Weiss, L.E.; Losee, J.E.; Campbell, P.G. Inkjet-based biopatterning of bone morphogenetic protein-2 to spatially control calvarial bone formation Tissue Eng. A 2010, 16, 1749-1759.

159. Grosberg, A.; Alford, P.W.; McCain, M.L.; Parker, K.K. Ensembles of engineered cardiac tissues for physiological and pharmacological study: Heart on a chip. Lab Chip 2011, 11, 4165-4173.

160. Kniazeva, T.; Hsiao, J.C.; Charest, J.L.; Borenstein, J.T. A microfluidic respiratory assist device with high gas permeance for artificial lung applications. Biomed. Microdevices 2011, 13, 315-323.

161. Sung, J.H.; Yu, J.; Luo, D.; Shuler, M.L.; March, J.C. Microscale 3-D hydrogel scaffold for biomimetic gastrointestinal (GI) tract model. Lab Chip 2011, 11, 389-392.

(C) 2012 by the authors; licensee MDPI, Basel, Switzerland. This article is an open access article distributed under the terms and conditions of the Creative Commons Attribution license (http://creativecommons.org/licenses/by/3.0/). 